\title{
Synthesis of Manganese Chloride Activated Carbon Deriving from Wheat Straw and its Adsorption Mechanism for Arsenic and Chromium
}

\author{
Ningyuan Zhu' ${ }^{1,2}$, Tingmei Yan ${ }^{1 *}$, Jun Qiao' and Honglei Cao ${ }^{1,2}$ \\ ${ }^{1}$ Institute of Soil Science, Chinese Academy of Sciences, No. 71 East Beijing Road, Nanjing 210008, China \\ ${ }^{2}$ Graduate School of the Chinese Academy of Sciences, Beijing 100039, China
}

\begin{abstract}
Manganese impregnated biochar deriving from wheat straw were synthesized to treat heavy metal contamination Nitrogen adsorption-desorption isotherms, scanning electron microscopy-energy dispersive X-Ray spectroscopy (SEM-EDS), and X-ray diffraction (XRD) were used to determine the characteristics of adsorbents. Batch adsorption experiments demonstrated a fit Langmuir model with the maximum adsorption capacity of $0.216 \mathrm{mmol} \mathrm{g}^{-1}$ for As (III) and a suitable Freundlich model for $\mathrm{Cr}(\mathrm{VI})$ respectively. Fourier transform infrared spectroscopy (FTIR) and X-ray photoelectron spectroscopy (XPS) were measured to explore probable adsorption mechanisms involving As and $\mathrm{Cr}$ adsorption, which indicated that the Lewis acid-base interactions play a more important role in arsenic adsorption while electrostatic interaction along with the reduction $\mathrm{Cr}(\mathrm{VI})$ to $\mathrm{Cr}$ (III) contribute primarily to chromium adsorption.
\end{abstract}

Keywords: Wheat straw; Manganese chloride; Activated carbon; Adsorption mechanism

\section{Introduction}

In the past few decades, discharging thousands of organic, inorganic, and biological pollutants into environment has severely deteriorated water quality especially the heavy metals pollution which could be concentrated in organisms and, thus, harmful to most plants and animals not only at a high dose but also in relatively low concentration [1]. The continuous existence of heavy metal contaminant in the water environment, such as the high toxic arsenic and chromium, has been threaten seriously to water resource. Many studies have applied various methods such as ion exchange, solvent extraction, chemical precipitation and adsorption to reduce the concentration of these kinds of metal ions $[2,3]$. Among these methods, adsorption has been proved to be the most commonly used technique due to its simplicity of design, high efficiency, ease of operation and heavy metal adsorbents like polymeric hybrid sorbent, manganese oxide modified biochar and akaganeite nanoparticles have been well investigated [4-6]. Pacheco et al. [7] prepared alumina silica nanoparticles with hydroxyl, alkoxy, and oxy groups, which could remove cadmium efficiently by cationic exchange from wastewater samples. Banerjee and Chen [8] modified magnetic $\mathrm{Fe}_{3} \mathrm{O}_{4}$ nanoparticles with gum arabic which could adsorb copper metal ion rapidly from aqueous solution due to carboxylic groups of gum arabic, complexation of the amine group of gum arabic and surface hydroxyl groups of iron oxide.

In addition, many authors have used natural Akadama clay, modified chitosan and activated carbon for removal chromium [911] and sorbents derived from iron and aluminium such as granular ferric hydroxide, Fe-loaded sponge and gibbsite for arsenic reduction [3,12-14]. Still, there are no low-cost and high effective methods and materials, even based on adsorption methods, for arsenic and chromium treatment, which predominantly exist in the inorganic anion forms of $\mathrm{AsO}_{2}^{-}(\mathrm{III}), \mathrm{AsO}_{4}^{3-}(\mathrm{V})$, and $\mathrm{Cr}_{2} \mathrm{O}_{7}^{2-}(\mathrm{VI})[11,15]$. Unfortunately, $\mathrm{Cr}$ (VI) is about one hundred to five hundred times more toxic than $\mathrm{Cr}$ (III) and toxicity of $\mathrm{Cr}$ (VI) can seriously destroy people's health including skin irritation, nausea, severe diarrhea, as well as lung, liver, and kidney damage because of its teratogenicity, mutagenicity, and carcinogenicity in biological systems [16,17]. Still, there are few researches had reported a cost-effective and eco-friendly material for lower of chromium and arsenic which are main existed as the anion forms and, thus, more difficult to be reduced $[16,18]$. Besides, the inorganic species arsenate
(As (V) at high redox potential value) and arsenite (As (III) at low redox potential value) were the predominant forms of as in aquatic environment. The trivalent $\mathrm{Cr}$ (III) and hexavalent forms $\mathrm{Cr}$ (VI) are the primarily form for chromium in natural water, which depends on the oxidative properties and $\mathrm{pH}$ level. Heavy metals, especially the chromium and arsenic, are more problematic and threatening to ecological environment and human beings because of their high toxicity, non-biodegradation and accumulation through food chain. Thus, the World Health Organization recommended the maximum permissible limit for arsenic is $10 \mu \mathrm{g} \mathrm{L}^{-1}$ while the maximum limit for chromium is $0.05 \mathrm{mg} \mathrm{L}^{-1}$ in drinking water $[15,17,19]$.

As (III), that can take up $67-99 \%$ of total arsenic in groundwater, is more problematic than As (V) because As (III) is more toxic and difficult to remove from water $[3,15]$. Since arsenic and chromium are highly toxic and carcinogenic, the maximum permissible limit for arsenic is $10 \mu \mathrm{g} / \mathrm{L}$ in drinking water according to the World Health Organization and the maximum contaminant level of chromium (VI) is $50 \mu \mathrm{g} / \mathrm{L}$ for potable water according to the United States Environment Protection Agency, respectively [10,12]. Therefore, it is very imperative to consider innovative and effective treatment options to meet the stringent arsenic and chromium standard.

Herein, to enhance their sorption capacity, the manganese chloride and wheat straw, which was one of the most abundant straw resources in China [20], were explored to prepare a low cost but high efficiency material for heavy metal treatment and straw utilization. The specific objectives of this work were to: (1) prepare and characterize $\mathrm{MnCl}_{2}$ impregnated biochar composites, (2) test its sorption capacities for As (III) and Cr (VI), and (3) investigate the possible mechanisms involved in the As (III) and Cr (VI) sorption.

*Corresponding authors: Tingmei Yan, Jun Qiao, Institute of Soil Science Chinese Academy of Sciences, No. 71 East Beijing Road, Nanjing 210008, China Tel: 8602586881308; E-mail: tmyan@issas.ac.cn, jqiao@issas.ac.cn

Received March 01, 2016; Accepted March 03, 2016; Published March 10, 2016

Citation: Zhu N, Yan T, Qiao J, Cao H (2016) Synthesis of Manganese Chloride Activated Carbon Deriving from Wheat Straw and its Adsorption Mechanism for Arsenic and Chromium. J Environ Anal Chem 3: 172. doi:10.417223802391.1000172

Copyright: (c) 2016 Zhu N, et al. This is an open-access article distributed under the terms of the Creative Commons Attribution License, which permits unrestricted use, distribution, and reproduction in any medium, provided the original author and source are credited. 


\section{Materials and Methods}

\section{Preparation of manganese activated carbon}

Stock solutions of $0.2 \mathrm{M}$ manganese chloride (Mn-solution) was prepared in a volumetric flask. $7.692 \mathrm{mmol} \mathrm{L}^{-1}$ sodium arsenite and $3.401 \mathrm{mmol} \mathrm{L}^{-1}$ potassium dichromate were prepared and diluted to the required concentrations with $0.01 \mathrm{M} \mathrm{NaCl}$. $\mathrm{MnCl}_{2} \cdot 4 \mathrm{H}_{2} \mathrm{O}$, sodium arsenite, potassium dichromate, sodium chloride and other reagents used in this work were all analytical grade.

Wheat straw was obtained from Wuxi city, Jiangsu province, China. Manganese activated carbon (MnBCs) were produced as follow: $100 \mathrm{ml} \mathrm{Mn}$-solution was mixed with wheat straw milled and sized to diameters $<0.80 \mathrm{~mm}$, stirred vigorously at $80^{\circ} \mathrm{C}$ for $3 \mathrm{~h}$, sonicated for 1 $\mathrm{h}$ and then dried at $105^{\circ} \mathrm{C}$. The biochar precursors were continuously heated to a target temperature $\left(300,400,500,600,700\right.$ and $\left.800^{\circ} \mathrm{C}\right)$ and finally maintained for $60 \mathrm{~min}$ in a furnace with the heating rate of $10^{\circ} \mathrm{C} \mathrm{m^{-1 }}$ under $100 \mathrm{ml} \mathrm{min}^{-1}$ nitrogen flow. Activated carbons were labelled as MnBC300, MnBC400, MnBC500, MnBC600, MnBC700 and $\mathrm{MnBC} 800$. The control biochar was also prepared by the same pyrolyzation process as manganese activated carbon under $500^{\circ} \mathrm{C}$ and labelled as CBC500.

\section{Sorption experiments}

Effect of $\mathrm{pH}$ on arsenic and chromium removal was investigated in a $100 \mathrm{ml}$ digestion vessels containing 0.1 gram adsorbent and 50 $\mathrm{ml}$ of $0.385 \mathrm{mmol} \mathrm{L}^{-1}$ sodium arsenite or $0.170 \mathrm{mmol} \mathrm{L}^{-1}$ potassium dichromate solution at room temperature. The $\mathrm{pH}$ level was adjusted at the range of 2-12 with hydrochloric acid and sodium hydroxide.

Adsorption isotherm experiments were conducted by mixing $0.1 \mathrm{~g}$ adsorbent with $50 \mathrm{ml}$ sodium arsenite with the concentration ranging from $0.038-1.538 \mathrm{mmol} \mathrm{L}^{-1}$ or potassium dichromate solutions with the concentration ranging from $0.017-0.680 \mathrm{mmol} \mathrm{L}^{-1}$ under the optimum $\mathrm{pH}$ level in a vessel. All the vessels above were shaken at $150 \mathrm{rpm}$ in the oscillator for $2 \mathrm{~h}$ and then placed in the water bath under constant temperature $\left(25^{\circ} \mathrm{C}\right)$ for $24 \mathrm{~h}$ to reach equilibrium. Inductive coupled plasma emission spectrometry (ICP) and Inductive coupled plasma emission spectrometry- mass spectrum (ICP-MS) were used to detect the concentration of arsenic and chromium.

\section{Characterization of adsorbents}

$\mathrm{N}_{2}\left(0.162 \mathrm{~nm}^{2}\right)$ adsorption-desorption experimental, scanning electron microscopy - energy spectrum analysis (SEM-EDS) and $\mathrm{X}$-ray diffraction were used to detective the surface characteristic of materials. Fourier transform infrared spectroscopy (FTIR) and X-ray photoelectron spectroscopy (XPS) were measured to explore probable adsorption mechanisms involving as and $\mathrm{Cr}$ adsorption.

\section{Results and Discussion}

\section{Characteristics of activated carbon}

$\mathbf{N}_{2}$ adsorption-desorption isotherms: In order to investigate the porosity of the $\mathrm{MnCl}_{2}$ activated carbon, nitrogen adsorption, a standard procedure for determination of the porosity of porous adsorbents, was used for determining its surface area and porous structure [21]. Figure 1 shown a reversible Type II isotherm which obtained with a non-porous or macropore adsorbent and represented unrestricted monolayer-multilayer adsorption. A type II isotherm contained a Point $\mathrm{B}$, the beginning of the almost linear middle section of the isotherm, indicating the end stage of monolayer coverage and the initiate of multilayer adsorption. The Point B was positioned very far forward on those line suggesting $\mathrm{MnBCs}$ possessed few tiny micropore structure.
Surface area and pore volume: Most of the pore size distributions of the activated carbons are between $20 \AA$ and $200 \AA$, which indicates that the carbons are mainly mesopore (Figure 2). Table 1 displayed the significant effect of carbonization temperature and manganese chloride on pore development and specific surface area. Specific surface area and pore volume increased with temperature escalating from 300 to $500^{\circ} \mathrm{C}$, decreased dramatically at $600^{\circ} \mathrm{C}$ and then enlarged again as temperature rising from 600 to $800^{\circ} \mathrm{C}$. The average pore diameter showed the opposite changing rule as the surface area and pore volume. Unexpectedly, the average pore diameter under a high carbonization temperature displayed a different variation trend from former investigation: the pore diameter did not increased, they decreased instead. In general, pore size distribution of activated carbon is dependent on activation temperature, raw material and retention time. Increasing the carbonization temperature within a certain temperature

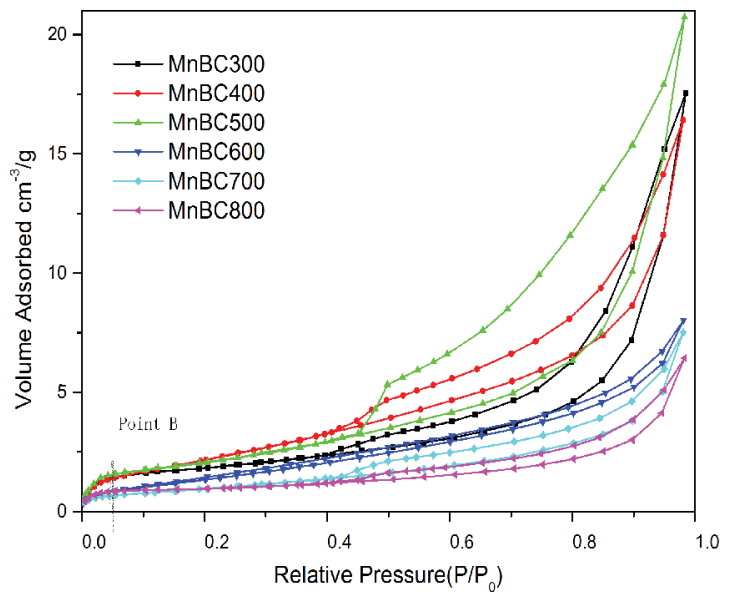

Figure 1: $\mathrm{N}_{2}$ adsorption-desorption isotherms of various activated carbons.

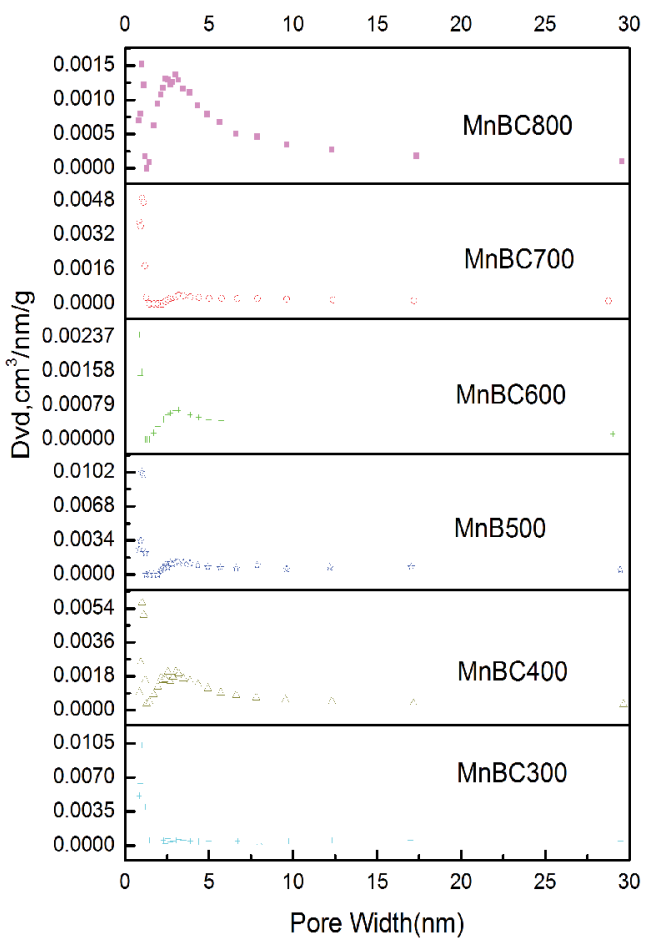

Figure 2: Pore distribution of MnBCs. 
range increases the evolution of volatile matters from the precursor, making the benefit of pore development, and creating new pores. The pyrolyzation effect, when out of the range, will cause the collapse of micropore and wide a significant amount of micropore to mesopore, quality just drop [22,23]. The abnormal variation trend under high pyrolyzation temperature indicated that the activating agent must make a difference in biochars pore structure and specific surface area.

SEM-EDS and XRD: Surface morphology and the main element of the activated carbon were investigated by scanning electron microscope (SEM) and energy spectrum analysis (EDS). The pore structure was observed obviously for the MnBC300, MnBC400 and MnBC500. The surface of MnBC600, however, was smooth and evidently absence of porosity. The pore structure appeared again for MnBC700 and became distinctly for MnBC800 (Figure 3). EDS results shown that the MnBCs were mainly contained carbon, oxygen, manganese and chloride (EDS was unable to detect the hydrogen element) (Table 2). The amount of chloride atom was almost as twice

\begin{tabular}{|c|c|c|c|c|}
\hline Sample & $\mathbf{S}_{\text {BET }}\left(\mathbf{m}^{2} \mathbf{g}\right)$ & $\mathbf{S}_{\text {External }}\left(\mathbf{m}^{2} / \mathbf{g}\right)$ & $\mathbf{D}_{\mathbf{p}}(\mathbf{n m})$ & $\mathbf{V}_{\text {Total }}\left(\mathbf{c m}^{3} / \mathbf{g}\right)$ \\
\hline MnBC300 & 17.27 & 9.239 & 16.01 & 0.027 \\
\hline MnBC400 & 19.35 & 6.352 & 16.51 & 0.030 \\
\hline MnBC500 & 19.47 & 8.009 & 10.99 & 0.035 \\
\hline MnBC600 & 6.732 & 3.765 & 12.3 & 0.012 \\
\hline MnBC700 & 8.88 & 2.998 & 10.15 & 0.011 \\
\hline
\end{tabular}

Table 1: Surface areas and pore volumes of activated carbons.

\begin{tabular}{|c|c|c|c|c|c|}
\hline \multirow{2}{*}{ MnBCs } & $\mathbf{C}$ & $\mathbf{O}$ & $\mathbf{N}$ & $\mathbf{C l}$ & Mn \\
\cline { 2 - 6 } & \multicolumn{5}{|c|}{ Element (wt\%) } \\
\hline MnBC300 & 43.64 & 14.02 & 1.68 & 23.88 & 16.78 \\
\hline MnBC400 & 46.5 & 7.6 & 0.82 & 23.01 & 22.07 \\
\hline MnBC500 & 51 & 5.54 & 0.31 & 21.59 & 21.56 \\
\hline MnBC600 & 44.6 & 4.72 & 0.62 & 24.47 & 25.59 \\
\hline MnBC700 & 53.85 & 5 & 0.53 & 19.9 & 20.72 \\
\hline MnBC800 & 45.42 & 6.22 & 0.88 & 23.4 & 24.08 \\
\hline
\end{tabular}

Table 2: ED's results of the main elements content of MnBCs.
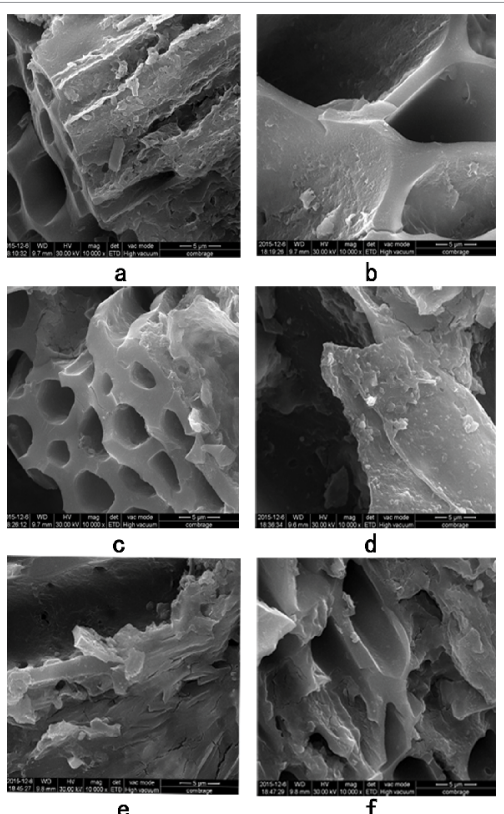

Figure 3: SEM of MnBCs: a, MnBC300; b, MnBC400; c, MnBC500; d, MnBC600; e, MnBC700 and f, MnBC800. as the manganese atom may indicating that a considerable number $\mathrm{MnCl}_{2}$, not the manganese oxide, still existed on the surface of those activated carbons. The X-ray diffraction could prove that hypothesis. The diffraction peaks were almost same for MnBC400, MnBC500, MnBC600, MnBC700 and MnBC800 (Figure 4). Diffraction peaks at $2 \theta=15.729,20.165$ and 31.879 which were corresponding to 110,020 and 021 planes respectively, for $\mathrm{MnCl}_{2}\left(\mathrm{H}_{2} \mathrm{O}\right)_{4}$ structure. The diffraction peaks for MnBC300 was obviously different from other MnBCs, which represented $\mathrm{MnCl}_{2}\left(\mathrm{H}_{2} \mathrm{O}\right)_{2}$. It is known that melting point of $\mathrm{MnCl}_{2}$ was almost $650^{\circ} \mathrm{C}$. Thus, we hypothesis that activating agent (melted liquid $\mathrm{MnCl}_{2}$ ) may inhibit the collapse of the micropore and even created new pore structure within the carbon matrix at 700 and $800^{\circ} \mathrm{C}$.

\section{Adsorption study}

Effect of $\mathbf{p H}$ and sorbent dosage: MnBC500 was chosen for adsorption study because of its highest specific surface area and pore volume. Prior to sorption study, the manganese chloride modified carbon was washed thoroughly to get rid of manganese chloride. The effect of initial solution $\mathrm{pH}$ level for adsorption of arsenic and chromium were studied firstly. The raw biochar (CBC500) removed few chromium and negligible arsenic. The removal efficiency of arsenic for MnBC500 went up gradually and then decreased with increasing the initial solution $\mathrm{pH}$ level (Figure 5). The maximum adsorption ability of As (III) was obtained at $\mathrm{pH} 9.5$, which was coincident with the first dissociation constant of $\mathrm{H}_{3} \mathrm{AsO}_{3}\left(\mathrm{pK}_{1}=9.23\right)$. Chromium adsorption was also affected dramatically by the initial solution $\mathrm{pH}$ value. Removal efficiency decreased with increasing initial $\mathrm{pH}$ value ranging from 2 to 12 .

Adsorption isotherm: Three widely used isotherm models, namely the Langmuir, Freundlich isotherm and Temkin models, were applied to fitted adsorption experimental data [24]. The Langmuir model (i.e., $\mathrm{L}$ model) assumed the repulsive interaction was inexistent among adsorbate particles and adsorption heat was homogeneous; Freundlich model (i.e., F model) was based on a multilayer adsorption condition with an inhomogeneous distribution of adsorption heat; Temkin isotherm (i.e., T model) assumed that the heat of adsorption decreased linearly. These equations could be expressed in the following form:

$$
\begin{aligned}
& \frac{C_{e}}{q_{e}}=\frac{C_{e}}{Q_{0}}+\frac{1}{b Q_{0}} \\
& q_{e}=\frac{R T}{b_{T}} \ln \mathrm{A}+\frac{R T}{b_{T}} \ln C_{e} \\
& q_{e}=\frac{R T}{b_{T}} \ln \mathrm{A}+\frac{R T}{b_{T}} \ln C_{e}
\end{aligned}
$$

Where $\mathrm{C}_{\mathrm{e}}\left(\mathrm{mmol} \mathrm{L}^{-1}\right)$ was the equilibrium concentration, and $\mathrm{q}_{\mathrm{e}}$ $\left(\mathrm{mmol} \mathrm{\textrm {g } ^ { - 1 }}\right)$ was the amount of adsorption capacity at equilibrium, respectively. $\mathrm{Q}_{0}\left(\mathrm{mmol} \mathrm{g}^{-1}\right)$ and $\mathrm{b}\left(\mathrm{L} \mathrm{mmol}^{-1}\right)$ were Langmuir constants. $\mathrm{K}_{\mathrm{f}}\left(\mathrm{mmol} \mathrm{g}^{-1}\right)$ and $\mathrm{n}$ were Freundlich constants. A $\left(\mathrm{L} \mathrm{mmol}^{-1}\right)$ and $\mathrm{b}_{\mathrm{T}}(\mathrm{J}$ $\mathrm{mol}^{-1}$ ) were Temkin constants. $\mathrm{T}$ was absolute temperature and $\mathrm{R}$ was universal gas constant $8.314 \mathrm{~J} \mathrm{~mol}^{-1} \mathrm{~K}^{-1}$. Results shown the $\mathrm{L}$ model was mostly suitable the equilibrium data of arsenic adsorption $\left(r^{2}>r_{T}^{2}>\right.$ $\mathrm{r}_{\mathrm{F}}^{2}$ ) assuming a monolayer adsorption process for As (Figure 6). The maximum adsorption capacity was $0.216 \mathrm{mmol} \mathrm{g}^{-1}$ for As (III) which was more excellent than other commonly used adsorbents reported in the literature. A dimensionless equilibrium parameter $\left(\mathrm{R}_{\mathrm{L}}\right)$ can further analysis of the Langmuir equation. The lower $R_{L}$ value means the more favorable adsorption provided at the range between 0 and 1 . The value of $R_{L}$ was $0.025-0.507$ for MnBC500 in the $C_{0}$ range of this study, implying 


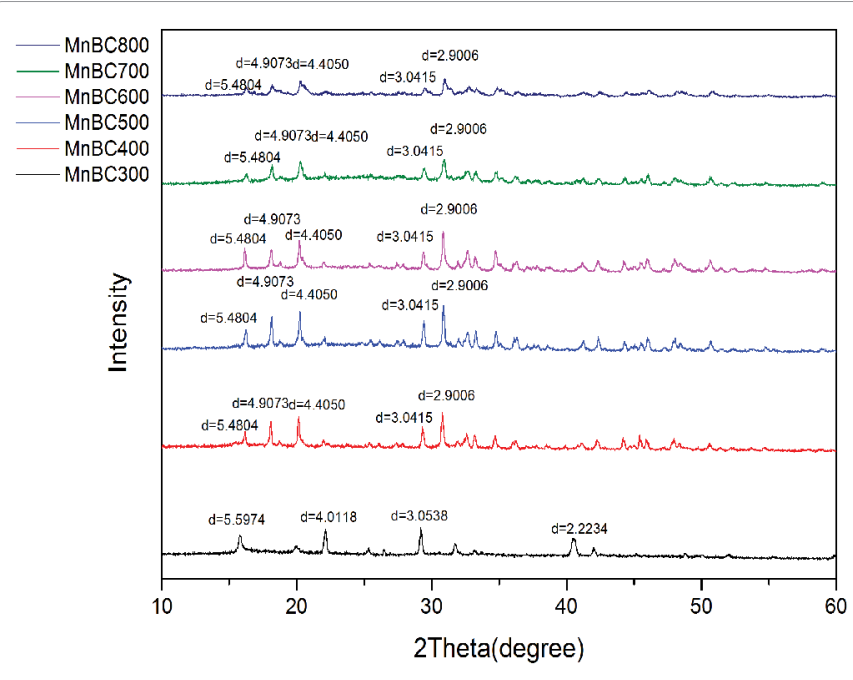

Figure 4: XRD pattern of MnBCs.

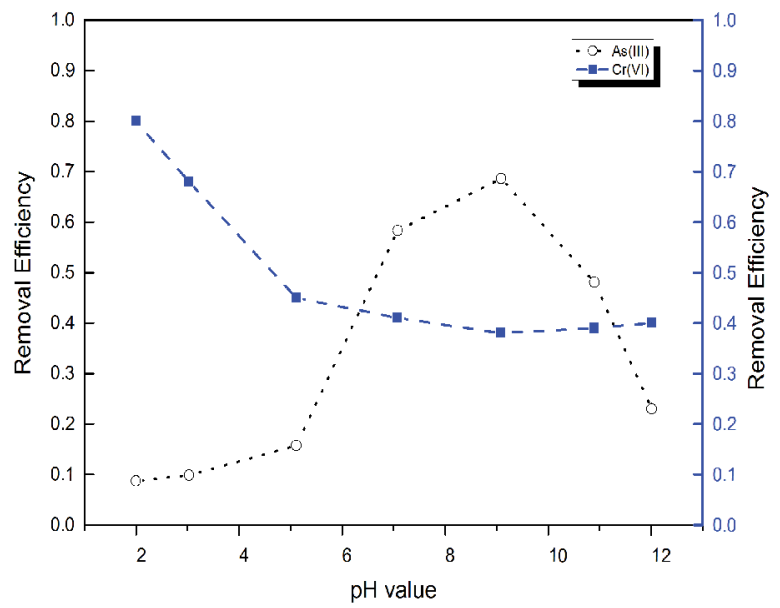

Figure 5: The effect of $\mathrm{pH}$ value on arsenic and chromium adsorption.

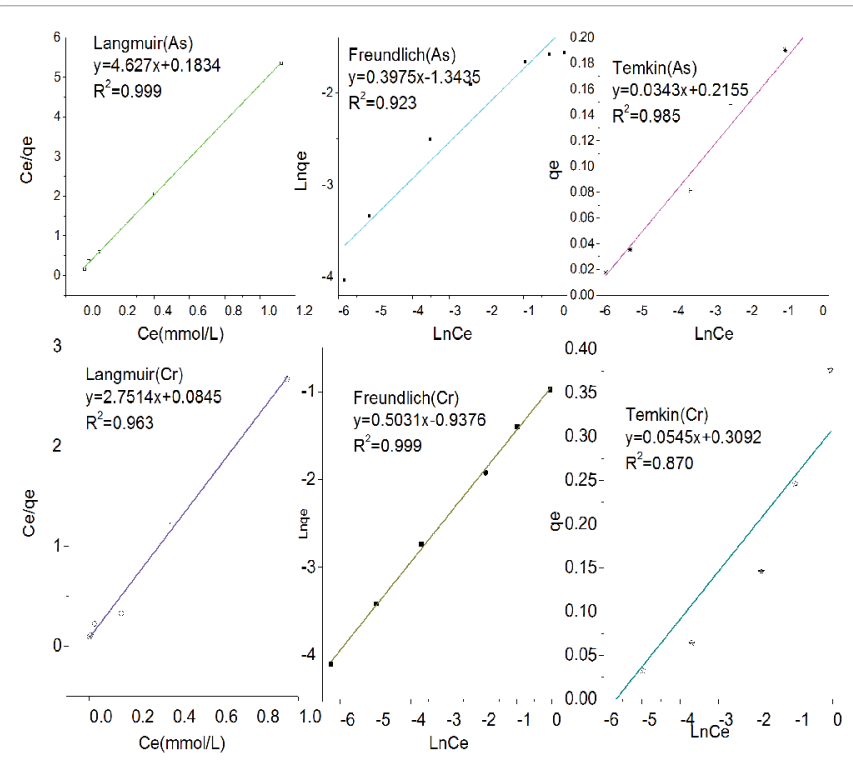

Figure 6: Three adsorption isotherm modes for arsenic and chromium adsorption a favorable arsenic adsorption process. The Temkin plots also had good linearity indicating the strong chemical interaction between adsorbate and adsorbent. These results illustrated the homogenous distribution of active sites over sorbent surface. Generally, the Langmuir model was suitable for the uniformly distributed metal salts, namely, the active sorption site to some certain contaminants on the surface of activated carbon. The Freundlich model, however, best fitted to the chromium sorption data $\left(\mathrm{r}_{\mathrm{F}}^{2}>\mathrm{r}_{\mathrm{L}}^{2}>\mathrm{r}_{\mathrm{T}}^{2}\right)$ suggesting a multilayer sorption process for chromium. This result may also indicated that those active adsorption sites were inoperative to chromium. The maximum $\mathrm{Cr}(\mathrm{VI})$ adsorption capacity was detected as $0.442 \mathrm{mmol} \mathrm{g}^{-1}$ in our study (Table 3 ).

\section{Adsorption mechanism}

FTIR: FTIR spectra of CBC500, MnBC500, MnAsBC500 and $\mathrm{MnCrBC500}$ were presented in Figure 4 to identify some important functional groups and the roles they played in adsorption process. The peaks at 3436, 2976, 1634, 1384, and $1045 \mathrm{~cm}^{-1}$ were related groups of biochar, which assigned in Table 4. The new peak at $617 \mathrm{~cm}^{-1}$ demonstrated the $\mathrm{Mn}^{2+}-\mathrm{O}$ lattice vibration band [25]. The vibration on $1634 \mathrm{~cm}^{-1}$ shift to $1604 \mathrm{~cm}^{-1}$ for MnBC500 suggesting the activation agent enhanced the formation of aromatic ring structure which possession the conjugated $\pi$ bond decreasing the vibrational force constant of $\mathrm{C}=\mathrm{C}$. These aromatic compounds are easy to take place nucleophilic substitution and nucleophilic addition (Figure 7b). It was reported that

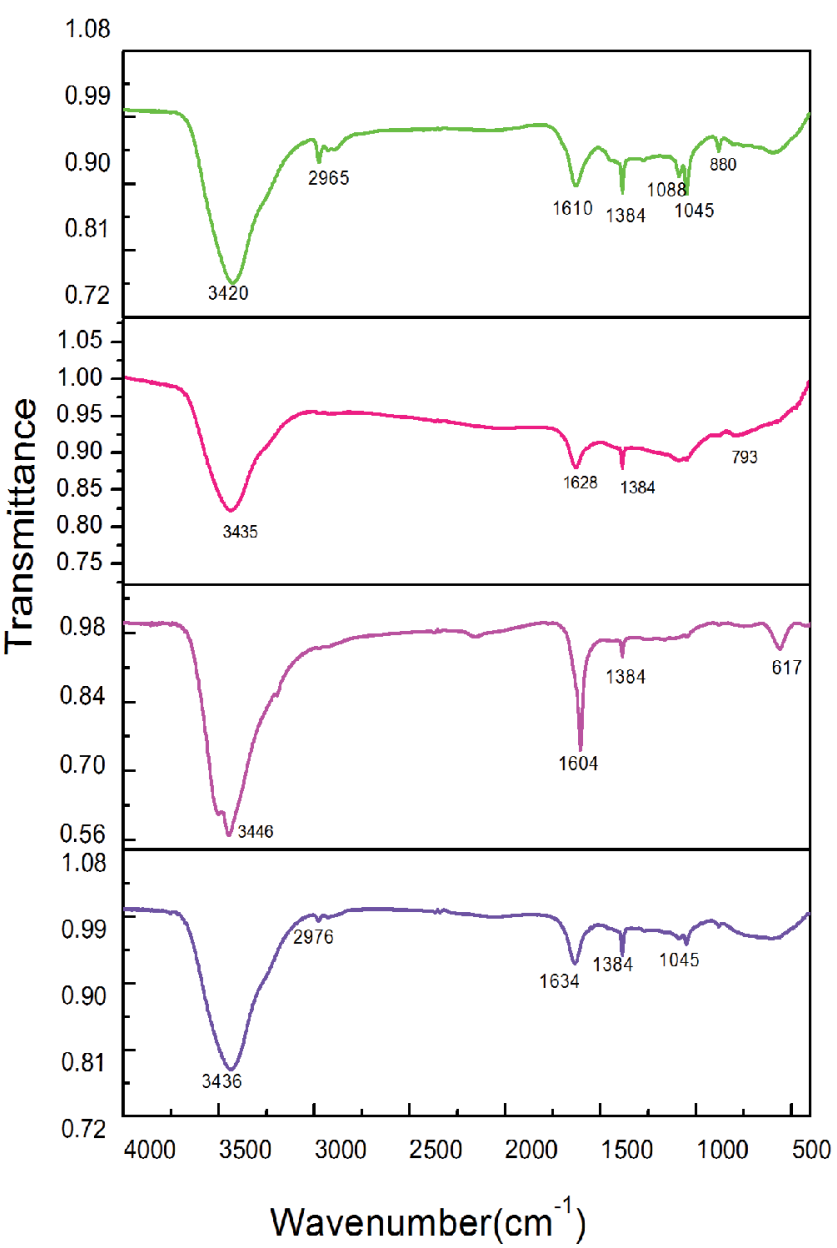

Figure 7: FTIR spectra for biochars: a, CBC500; b, MnBC500; c, MnCrBC500 d, MnAsBC500. 
the characteristic absorption bands of adsorbed arsenate was 650-950 $\mathrm{cm}^{-1}$ for As-OH or As-O stretching vibration [26]. Peak at $793 \mathrm{~cm}^{-1}$ represented a weak As -O bond suggesting As (III) surface complex was non-protonated $[27,28]$ while peak at $876 \mathrm{~cm}^{-1}$ may implying the As-OH vibration. Only a new peak at $880 \mathrm{~cm}^{-1}$ was observed after $\mathrm{Cr}$ adsorption. However, this peak has no relation with $\mathrm{Cr}-\mathrm{O}$.

XPS investigation: XPS was used to further investigate the mechanism of arsenic sorption on the manganese modified biochars as well as chromium adsorption mechanism (Figure 8). A manganese peaks corresponding to $\mathrm{Mn} 2 \mathrm{p}$ was found in the surface of $\mathrm{Mn}$ impregnated biochar both before and after as interaction. The binding energy $641.7 \mathrm{eV}$ represented the existence of $\mathrm{MnO}$ structure while the binding energy $653.7 \mathrm{eV}$ suggested a higher valency of manganese (III) $[29,30]$. The higher valency of manganese like Mn(IV) and Mn(III) had the ability to oxide As (III) to As (V) which was more easier to adsorbed by manganese oxide [31]. However, there was no obvious decrease of Mn (III) content or increase of Mn (II) after arsenic adsorption. Prominent peak corresponding to As3d was observed in the surface of MnAsBC500 and the binding energy was 48.75 suggesting As (III) oxidation was not happen. The former researches has demonstrated As (V) could be adsorbed through the electrostatic force as well as ligand exchange reactions while the As (III) adsorption was mainly involved ligand exchange reaction [13]. Thus, the main adsorption mechanism could be attributed to the ligand reaction between the manganese and arsenite. If we can control the oxygen content to form a high valency
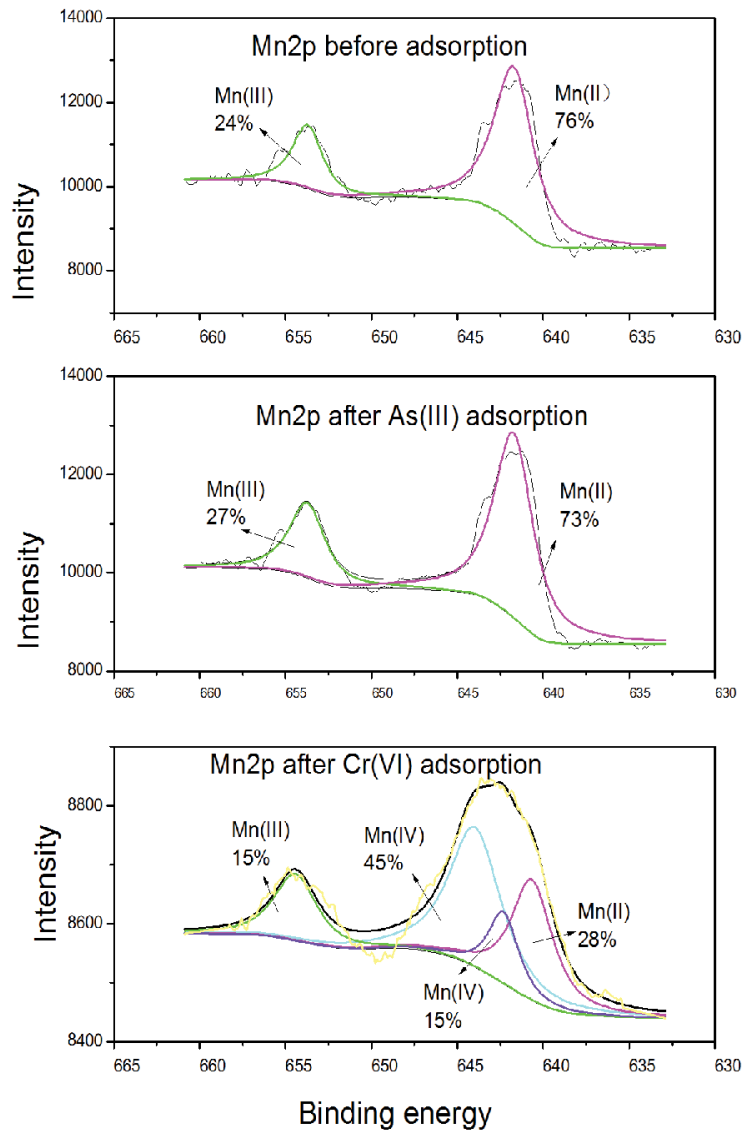

manganese oxide, the arsenic adsorption capacity may be further enhanced. Nevertheless, the definite structure of Mn-As complexes needs to be further studied. That is our ongoing research work.

Meanwhile, during the chromium sorption process, the $72 \%$ of manganese (II) atoms are oxidized to $\mathrm{Mn}$ (III) and Mn (IV), which was illustrated in Figure 8. Consequently, the adsorbed $\mathrm{Cr}$ (VI) could be reduced to $\mathrm{Cr}$ (III) via reaction with the $\mathrm{Mn}$ (II) (Figure 8). This results suggested that chromium adsorption mechanism was related to the reduction $\mathrm{Cr}$ (VI) to $\mathrm{Cr}$ (III) along with the electrostatic phenomenon.

\section{Conclusion}

Based on experimental results, manganese chloride activated carbons derived from wheat straw were synthesized and shown high sorption ability to arsenic and chromium. Bach sorption experiments shown a fitted Langmuir model for arsenic adsorption while a suitable Freundlich model for chromium adsorption. Ligand exchange contributed mainly to arsenic removal while electrostatic phenomenon with the chromium reduction played an important role in chromium sorption. This work demonstrated that manganese modified biochar provides an innovative and effective way to utilize straw resources by preparing low-cost adsorbents for heavy metal pollutants treatment.

\section{Acknowledgements}

This study was funded by the National Natural Science Foundation of China (41171236), the National Key Technology R\&D Program of China (2012BAD15B03) and the National S\&T Major Project of China (2012ZX07204-003).
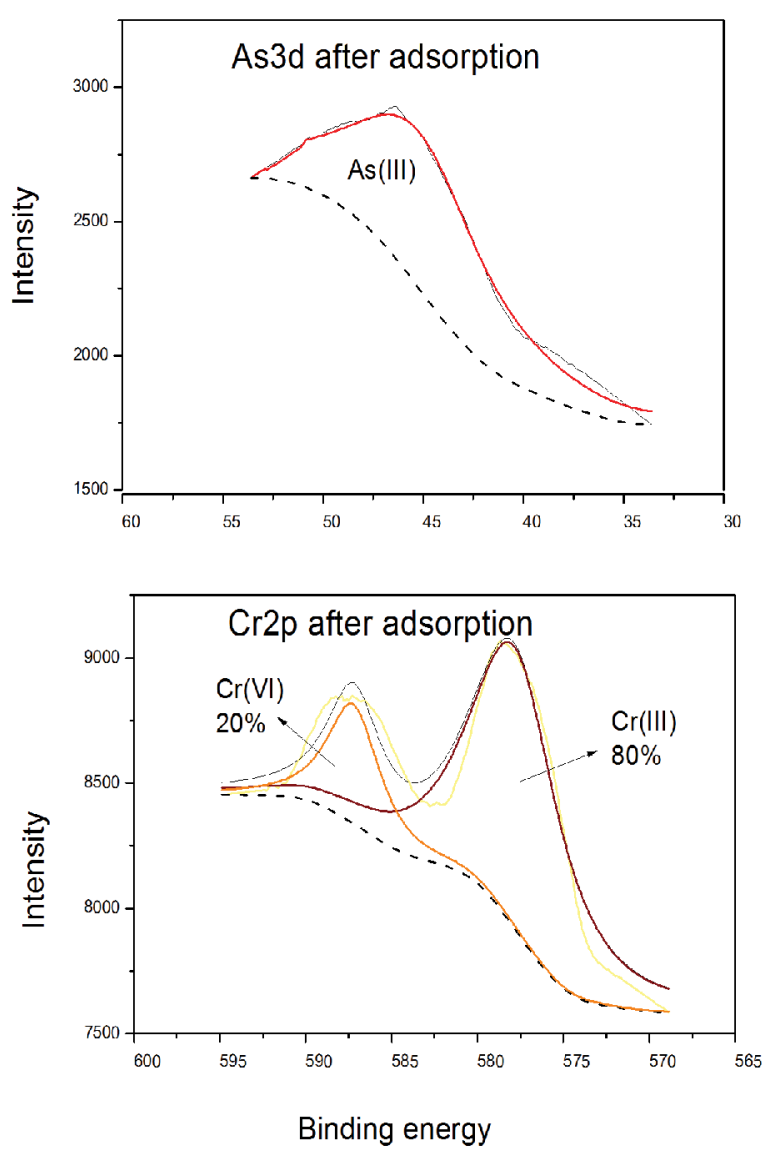

Figure 8: High-resolution XPS spectra for Mn2p, As3d and Cr2p regions of MnBC500, MnAsBC500 and MnCrBC500. 
Citation: Zhu N, Yan T, Qiao J, Cao H (2016) Synthesis of Manganese Chloride Activated Carbon Deriving from Wheat Straw and its Adsorption Mechanism for Arsenic and Chromium. J Environ Anal Chem 3: 172. doi:10.41722380-2391.1000172

\begin{tabular}{|c|c|c|c|c|c|c|}
\hline \multirow{2}{*}{$\begin{array}{c}\text { Temperature } \\
\text { (K) }\end{array}$} & \multicolumn{3}{|c|}{ Langmuir parameters } & \multicolumn{3}{|c|}{ Thermodynamics } \\
\hline & $\underset{(\mathrm{mmol} / \mathrm{g})}{Q_{0}}$ & b & $\mathbf{R}^{2}$ & $\begin{array}{c}\Delta \mathbf{G}^{\circ} \\
\left(\mathbf{k J} \mathrm{mol}^{-1}\right)\end{array}$ & $\begin{array}{c}\Delta \mathrm{H}^{\circ} \\
\left(\mathrm{kJ} \mathrm{mol}^{-1}\right)\end{array}$ & $\begin{array}{c}\Delta \mathbf{S}^{\circ} \\
\left(\mathrm{kJ} \mathrm{mol}^{-1}\right)\end{array}$ \\
\hline 283 & 0.183 & 10.75 & 0.992 & -33.2 & & \\
\hline 298 & 0.216 & 25.24 & 0.999 & -35.13 & 0.15 & 9.55 \\
\hline 318 & 0.268 & 28.22 & 0.999 & -37.45 & & \\
\hline
\end{tabular}

Table 3: Parameters of Langmuir isotherms and thermodynamics of As (III) adsorption.

\begin{tabular}{|c|c|}
\hline Wave number $\left(\mathbf{c m}^{-1}\right)$ & Characteristic vibrations \\
\hline 3446 & O-H stretching of H-bonded hydroxyl \\
\hline 2976 & C-H stretching vibration \\
\hline 1634 & $\mathrm{C}=\mathrm{C}$ stretching of aromatic ring \\
\hline 1384 & $\mathrm{C}-\mathrm{H}$ bending of $\mathrm{CH}_{3}$ (symmetric) groups \\
\hline 1045 & $\mathrm{C}-\mathrm{O}$ stretching of $\mathrm{C}-\mathrm{OH}$ groups \\
\hline
\end{tabular}

Table 4: Assignment of the main characteristic vibrations of biochar's FT-IR spectrum.

\section{References}

1. Pan JJ, Jiang J, Xu RK (2014) Removal of $\mathrm{Cr}(\mathrm{VI})$ from aqueous solutions by $\mathrm{Na}_{2} \mathrm{SO}_{3} / \mathrm{FeSO}_{4}$ combined with peanut straw biochar. Chemosphere 101: 71-76.

2. Hua M, Zhang S, Pan B, Zhang W, Lv L, et al. (2012) Heavy metal removal from water/wastewater by nanosized metal oxides: a review. J Hazard Mater 211-212: 317-31.

3. Giles DE, Mohapatra M, Issa TB, Anand S, Singh P (2011) Iron and aluminium based adsorption strategies for removing arsenic from water. J Environ Manage 92: 3011-3022

4. Afkhami, Saber-Tehrani M, Bagheri H (2010) Simultaneous removal of heavy-metal ions in wastewater samples using nano-alumina modified with 2,4-dinitrophenylhydrazine. Journal of Hazardous Materials 181: 836-844.

5. Zhang Q, Pan B, Pan B, Zhang W, Jia K, et al. (2008) Selective sorption of lead, cadmium and zinc ions by a polymeric cation exchanger containing nano$\mathrm{Zr}(\mathrm{HPO} 3 \mathrm{~S}) 2$. Environ Sci Technol 42: 4140-4145.

6. Wang S, Gao B, Li Y, Mosa A, Zimmerman AR, et al. (2015) Manganese oxidemodified biochars: preparation, characterization, and sorption of arsenate and lead. Bioresour Technol 181: 13-17.

7. Pacheco S, Tapia J, Medina M, Rodriguez R (2006) Cadmium ions adsorption in simulated wastewater using structured alumina-silica nanoparticles. J NonCryst Solids 352: 5475-5481.

8. Banerjee SS, Chen DH (2007) Fast removal of copper ions by gum arabic modified magnetic nano-adsorbent. J Hazard Mater 147: 792-799.

9. Baran A, Biçak E, Baysal SH, Onal S (2007) Comparative studies on the adsorption of $\mathrm{Cr}(\mathrm{VI})$ ions on to various sorbents. Bioresour Technol 98: 661-665.

10. Giri AK, Patel R, Mandal S (2012) Removal of $\mathrm{Cr}$ (VI) from aqueous solution by Eichhornia crassipes root biomass-derived activated carbon. Chemical Engineering Journal 185-186 71-81.

11. Zhao Y, Yang S, Ding D, Chen J, Yang Y, et al. (2013) Effective adsorption of $\mathrm{Cr}(\mathrm{VI})$ from aqueous solution using natural Akadama clay. J Colloid Interface Sci 395: 198-204.

12. Banerjee K, Amy GL, Prevost M, Nour S, Jekel M, et al. (2008) Kinetic and thermodynamic aspects of adsorption of arsenic onto granular ferric hydroxide (GFH). Water Res 42: 3371-3378.

13. Munoz JA, Gonzalo A, Valiente M (2002) Arsenic adsorption by Fe (III)loaded open-celled cellulose sponge. Thermodynamic and selectivity aspects. Environmental Science \& Technology 36: 3405-3411.

14. Duarte G, Ciminelli VST, Dantas MSS, Duarte HA, Vasconcelos IF, et al. (2012) As (III) immobilization on gibbsite: Investigation of the complexation mechanism by combining EXAFS analyses and DFT calculations. Geochimica et Cosmochimica Acta 83: 205-216.

15. Liu G, Zhang X, Talley JW, Neal CR, Wang H (2008) Effect of NOM on arsenic adsorption by $\mathrm{TiO}(2)$ in simulated $\mathrm{As}(\mathrm{III})$-contaminated raw waters. Water Res 42: $2309-2319$.

16. Alemayehu E, Thiele-Bruhn S, Lennartz B (2011) Adsorption behaviour of $\mathrm{Cr}(\mathrm{VI})$ onto macro and micro-vesicular volcanic rocks from water. Separation and Purification Technology 78: 55-61.
17. Tang WW, Zeng GM, Gong JL, Liang J, Xu P, et al. (2014) Impact of humic/ fulvic acid on the removal of heavy metals from aqueous solutions using nanomaterials: A review. Science of The Total Environment 468-469: 10141027.

18. Onnby L, Kumar PS, Sigfridsson KG, Wendt OF, Carlson S, et al. (2014) Improved arsenic(III) adsorption by $\mathrm{Al}_{2} \mathrm{O}_{3}$ nanoparticles and $\mathrm{H}_{2} \mathrm{O}_{2}$ : evidence of oxidation to arsenic $(\mathrm{V})$ from $\mathrm{X}$-ray absorption spectroscopy. Chemosphere 113: $151-157$

19. Wang XS, Chen LF, Li FY, Chen KL, Wan WY, et al. (2010) Removal of Cr (VI) with wheat-residue derived black carbon: reaction mechanism and adsorption performance. J Hazard Mater 175: 816-822.

20. Wang JY, Bi YY, Gao CY (2010) The Assessment and Utilization of Straw Resources in China, Agricultural Sciences in China 9: 1807-1815.

21. Onal Y, Akmil-BaÅŸar C, Sarici-Ozdemir C, ErdoÄŸan S (2007) Textural development of sugar beet bagasse activated with $\mathrm{ZnCl} 2$. J Hazard Mater 142 138-143.

22. Olivares-Marín M, Fernández-González C, Macías-García A, Gómez-Serrano $V$ (2006) Preparation of activated carbon from cherry stones by chemical activation with $\mathrm{ZnCl}_{2}$. Applied Surface Science 252: 5967-5971.

23. Demiral H, GÃ $1 / 4 n d \tilde{A} 1 / 4 Z 0 A ̈ \ddot{Y l u ~ G ~(2010) ~ R e m o v a l ~ o f ~ n i t r a t e ~ f r o m ~ a q u e o u s ~}$ solutions by activated carbon prepared from sugar beet bagasse. Bioresour Technol 101: 1675-1680.

24. Davis CW, Di Toro DM (2015) Modeling Nonlinear Adsorption to Carbon with a Single Chemical Parameter: A Lognormal Langmuir Isotherm. Environ Sci Technol 49: 7810-7817.

25. Kang L, Zhang M, Liu ZH, Ooi K (2007) IR spectra of manganese oxides with either layered or tunnel structures. Spectrochim Acta A Mol Biomol Spectrosc 67: 864-869.

26. Hu X, Ding Z, Zimmerman AR, Wang S, Gao B (2015) Batch and column sorption of arsenic onto iron-impregnated biochar synthesized through hydrolysis. Water Res 68: 206-216.

27. Goldberg S, Johnston CT (2001) Mechanisms of arsenic adsorption on amorphous oxides evaluated using macroscopic measurements, vibrational spectroscopy, and surface complexation modeling. J Colloid Interface Sci 234 204-216.

28. Pena M, Meng X, Korfiatis GP, Jing C (2006) Adsorption mechanism of arsenic on nanocrystalline titanium dioxide. Environ Sci Technol 40: 1257-1262.

29. Carver JC, Carlson TA, Schweitz Gk (1972) Use Of X-Ray Photoelectron Spectroscopy to Study Bonding In Cr, Mn, Fe, And Co Compounds. J Chem Phys 57: 973.

30. Franzen HF, Umana MX, McCreary JR, Thorn RJ (1976) Xps Spectra of Some Transition-Metal And Alkaline-Earth Monochalcogenides. Journal of Solid State Chemistry 18: 363-368.

31. Nesbitt HW, Canning GW, Bancroft GM (1998) XPS study of reductive dissolution of 7 angstrom-birnessite by $\mathrm{H}_{3} \mathrm{AsO}_{3}$, with constraints on reaction mechanism. Geochimica Et Cosmochimica Acta 62: 2097-2110. 